
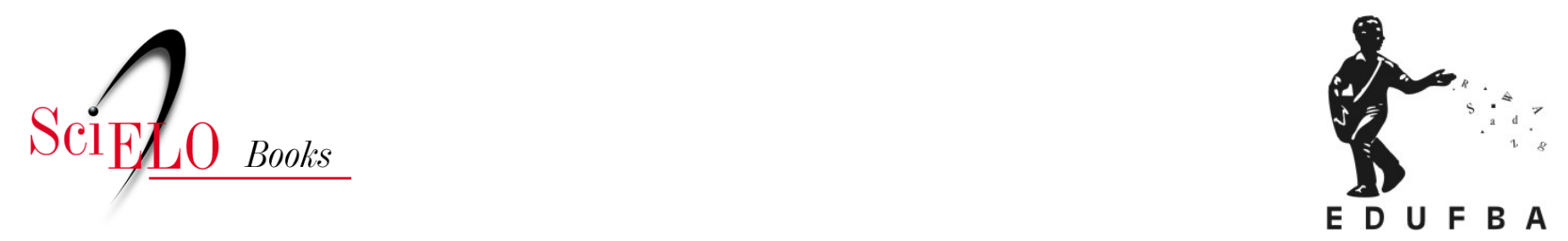

\title{
Marisqueiras da Ilha das Fontes descrição do trabalho e da tradição incorporadas na pesca artesanal
}

\author{
Thais Mara Dias Gomes \\ Mônica Angelim Gomes de Lima \\ Maria do Carmo Soares de Freitas
}

\section{SciELO Books / SciELO Livros / SciELO Libros}

GOMES, T.M.D., LIMA, M.A.G. and FREITAS, M.C.S. Marisqueiras da llha das Fontes: descrição do trabalho e da tradição incorporadas na pesca artesanal. In: FERNANDES, R.C.P., LIMA, M.A.G., and ARAÚJO, T.M., comps. Tópicos em saúde, ambiente e trabalho: um olhar ampliado [online]. Salvador: EDUFBA, 2014, pp. 129-152. ISBN: 978-65-5630-012-2. https://doi.org/10.7476/9786556300122.0008.

\section{International license.}

Todo o conteúdo deste trabalho, exceto quando houver ressalva, é publicado sob a licença Creative Commons Atribição 4.0. 


\section{Marisqueiras da Ilha das Fontes: descrição do trabalho e da tradição incorporadas na pesca artesanal}

Thais Mara Dias Gomes

Mônica Angelim Gomes de Lima Maria do Carmo Soares de Freitas

\section{Introdução}

A temática da saúde do trabalhador artesanal em geral é pouco explorada. Verificam-se relatos históricos como o do médico Bernadino Ramazzini (1985), pioneiro em descrever sistematicamente doenças do trabalho para 54 profissões artesanais, dentre elas, o ofício de pescador e suas respectivas doenças profissionais. Há de se ressaltar que o estudo em questão transita na pesca tradicional marítima e fluvial e não na atividade de extração de mariscos.

A construção da Saúde do Trabalhador envolve o reconhecimento da multiplicidade de mundos do trabalho e, por isso, suas práticas devem adotar abordagens inclusivas de categorias tradicionais. A pesca artesanal representa um desses desafios. Trata-se de homens, crianças e principalmente mulheres expostas aos mais variados riscos e a processos de adoecimento sem acesso à proteção da saúde dos trabalhadores. São categorias de trabalhadores vulneráveis no mundo contemporâneo, em condições de pobreza e que resistem à gigantesca hegemonia da sociedade industrial e terciária, preservando o saber-fazer do pescador artesanal/marisqueira. 
O Brasil apresenta uma extensão litorânea de cerca de 8.500 quilômetros e uma Zona Economicamente Exclusiva - ZEE ${ }^{1}$ de 3,5 milhões de $\mathrm{km}^{2}$, representados principalmente pela região Nordeste. (IBAMA, 2006) O estado da Bahia possui 427 milhas e cerca de $800 \mathrm{~km}$ em linha reta. Ao considerar as reentrâncias, essa distância aproxima-se de 1.200 $\mathrm{km}$, representando $14 \%$ da costa brasileira. (IBAMA, 2006) As áreas denominadas Litoral Norte, Baía de Todos os Santos/Recôncavo, Baixo Sul, Litoral Sul e Extremo Sul são formadas por 44 municípios, estando inseridas 347 comunidades pesqueiras, sendo 9 delas localizadas no município de São Francisco do Conde ${ }^{2}$. (BAHIA, 2005)

Esse vasto litoral (Figura 1) possui um grande número de estuários, formando um complexo de manguezais e coroas. Segundo Marta Vannuci (1999), a pesca artesanal/mariscagem brasileira ocorre principalmente nos ambientes de mangue, possuindo o Brasil a segunda maior área do mundo, com cerca de $25.000 \mathrm{Km}^{2}$. ( $\mathrm{IUCN}^{3}, 1983$ )

Neste enorme complexo de manguezais, ecossistema cuja riqueza biótica é fartamente comprovada, habitam espécies que possuem parte ou todo o seu ciclo de vida nesses ambientes.

Nos ambientes existentes entre os manguezais e os estuários dos rios, locais onde ocorre a mistura entre as águas marinhas salgadas e as águas doces, encontra-se uma variedade de mariscos. Sob o domínio de marés, a movimentar-se quatro vezes por dia o ambiente marítimo oferta mariscos como Crassostrea rhizophorae "ostra do mangue" (Figura 1).

1 Um novo conceito de espaço marítimo foi introduzido a partir da criação de ZEE que dá uma série de direitos ao estado dela detentor. Direitos exclusivos de soberania para fins de exploração e aproveitamento, conservação e gestão dos recursos naturais, vivos ou não vivos, das águas sobrejacentes ao leito do mar, do leito e seu subsolo, bem como para a produção de energia a partir da água, marés, correntes e ventos. (IBAMA, 2006)

2 Comunidades pesqueiras de São Francisco do Conde: Sede, Caipe, Engenho de Baixo, Ilha das Fontes, Madruga, Monte Recôncavo, Ilha do Pati, Santo Estevão e Paramirim.

3 IUCN - International Union for Conservation of Nature and Natural Resources. A União Internacional para Conservação da Natureza e Recursos Naturais contribui nas soluções para os principais desafios ambientais e os problemas enfrentados no planeta, com atuação continental em temas como biodiversidade, mudanças climáticas e energia. 
Figura 1 - Crassostrea rhizophorae "ostra do mangue"

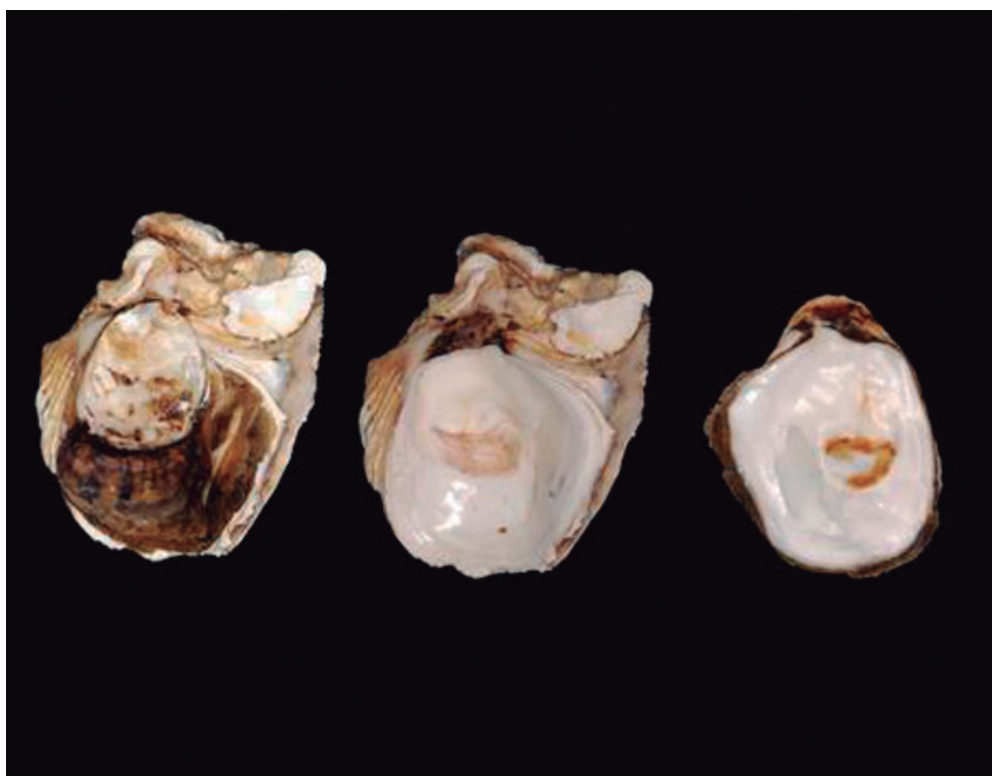

Fonte: (GOMES, 2011)

A Organização Internacional do Trabalho (OIT) estima um contingente de 25 a 34 milhões de homens e mulheres, envolvidos na pesca no âmbito global, sendo aproximadamente $75 \%$ artesãos. (ARNASON, 1998) Segundo dados do Registro Geral da Pesca (RGP) do Ministério da Pesca e Aquicultura, até 31/12/2009 estavam registrados 833.205 pescadores profissionais, distribuídos nas 26 Unidades da Federação e no Distrito Federal.

A região Nordeste concentra o maior número de pescadores, com 386.081 , que representa $46,3 \%$ do total do país, seguida pela Região Norte, com 266.476 (31,9\%). Juntas, essas regiões respondem por $78,3 \%$ do universo de pescadores profissionais do Brasil. (BRASIL, 2011) Organizações não governamentais adiantam que esses números podem chegar ao dobro do oficial, considerando o alto grau de informalidade típica das atividades desses povos das águas que sobrevivem cultuando tradições milenares.

O estado da Bahia possui um total de 105.455 mil pescadores cadastrados, sendo $54,9 \%$ do sexo masculino e $45,1 \%$ do sexo feminino, ocupando o primeiro lugar na Região Nordeste em quantidade de pescadores cadastrados. (BRASIL, 2011) 
A falta de informação ocorre em decorrência da pesca, quase sempre, está associada à atividade em alto mar, provavelmente porque o principal produto da sua captura, o peixe, é simbolizado pelo pescador, no barco, em mar aberto. (LEITÃO, 2009) Corrobora com esse cenário a forma de pesagem do marisco acontecer com o produto final já beneficiado. Essa ideia contribui para que as atividades desenvolvidas pelas mulheres no setor pesqueiro não sejam abordadas claramente nos estudos, ou apareçam como uma prática de complemento à renda familiar. Há uma carência significativa de informações sobre as particularidades do gênero no setor pesqueiro 4 . Segundo o Centro de Estudos e Pesquisas Josué de Castro (2000), a pesca e a coleta realizada por mulheres constituem um trabalho invisível.

As culturas tradicionais coexistem na relação do homem com o meio natural, com práticas, valores e conhecimentos empíricos adquiridos e acumulados através das várias gerações. (DIEGUES, 2004) Nesse contexto o homem modifica o meio assim como o meio impõe ao homem suas características, tornando-se parte de sua cultura. Em meio ao processo adaptativo de sobrevivência, as comunidades tradicionais desenvolvem técnicas produtivas inseridas num processo de produção particular, o da pequena produção mercantil. (DIEGUES, 1983)

O corpo de saberes que orienta o comportamento e as estratégias de pesca e mariscagem é essencial para prever situações em que a pesca pode ser produtiva. Sem esse conhecimento preciso seria impossível à sobrevivência e reprodução dessas comunidades num ambiente marinho sujeito a frequentes e perigosas mudanças de tempo.

A realização das tarefas não é uma situação estática ou padronizada, pode variar de uma comunidade para outra, assim como o perfil socioeconômico da região também se altera como descreve o Centro de estudos e pesquisas Josué de Castro (2000). Mais do que uma atividade econômica, a pesca artesanal/mariscagem no Brasil revela-se como um modo de vida, como um elemento organizador das demais dimensões da vida social. (DIEGUES, 2004)

Por ser o artesão o proprietário dos meios de produção, a concepção do trabalho e a execução encontravam-se unidas. Ao invés

4 Dados da Rede Latino Americana das Mulheres no Setor Pesqueiro - organização suportada pela FAO (Food and Agriculture Organization) a qual o Brasil está inserido. Fonte: http:// mujeres.infopesca.org 
de controlado pelo processo da produção, é o homem que o domina, submetendo-o à sua vontade. Portanto, é necessária uma inflexão nos elementos característicos do processo de produção artesanal, dentre os elementos característicos, inexiste um mercado de compra e venda da força de trabalho, com formalidades contratuais trabalhistas, situação de emprego e desemprego. (PENA; FREITAS; CADIM, 2011) Ressalta-se que pescador artesanal possui uma lógica diferenciada na relação com a natureza o que lhe permite transitar em seu meio através do domínio de sua técnica.

$\mathrm{Na}$ tentativa de se aproximar desta realidade, as autoras se propõem a descrever uma comunidade pesqueira em São Francisco do Conde, a Ilha das Fontes. É a partir da compreensão desse espaço que se apresenta o cenário da pesquisa. 'Em cena', as mulheres pescadoras/ marisqueiras e as próprias autoras numa perspectiva compreensiva, tomada por uma problemática que emerge do campo empírico e transita pelo simbólico. Neste sentido, buscou-se descrever o trabalho de pescadoras/marisqueiras na extração da ostra, apresentando as tarefas e o contexto temporal em que são executadas, compreender o cotidiano de vida e os significados da dor no trabalho de mariscagem.

\section{Métodos}

Trata-se de uma abordagem etnográfica na comunidade pesqueira de Ilha das Fontes/São Francisco do Conde. Foram utilizadas entrevistas em profundidade, conversas informais, registro de observação participante do cotidiano da Ilha: trabalho na maré, ambiente doméstico, áreas de lazer como praças e bares, espaços religiosos, análise do trabalho e análise documental. Para condução das entrevistas partiu-se de uma pergunta disparadora sobre como ser ou tornar-se marisqueira na Ilha das Fontes.

Optou-se pela perspectiva fenomenológico-compreensiva como referencial metodológico, pois ao longo desse campo foi privilegiada a interação e auto-observação para construção do entendimento. Esse estudo requereu uma aproximação com a ergonomia da Escola Francesa como referencial teórico na análise e compreensão do trabalho na maré.

Assume-se a Antropologia Interpretativa orientada pela perspectiva hermenêutica, dominante na fenomenologia compreensiva na 
construção desse trabalho. Como refere François Laplantine (2003, p. 121, 122),

[...] o etnógrafo é aquele que deve ser capaz de viver nele mesmo a tendência principal da cultura que estuda. [...] uma verdadeira aculturação invertida, na qual, longe de compreender uma sociedade apenas em suas manifestações “exteriores" (Durkheim), devo interiorizá-la nas significações que os próprios indivíduos atribuem a seus comportamentos.

Esse "encontro etnográfico" requer "um olhar devidamente sensibilizado pela teoria disponível”. (OLIVEIRA, 1998, p. 19) Dessa forma, a observação participante sobre o trabalho etnográfico formulada em termos hermenêuticos é uma dialética entre a experiência e a interpretação. (GEERTZ, 1989) Como afirma Paul Ricoeur (1978), essa hermenêutica, explicita ou implicitamente, permite conhecer a si mesmo mediante a compreensão do outro.

O primeiro momento da pesquisa consistiu na identificação de uma comunidade pesqueira do município de São Francisco do Conde/BA 5 . Existem no município de São Francisco do Conde nove comunidades que sobrevivem da pesca artesanal. Ao analisar a realidade de acesso aos serviços de saúde, distância da sede e localização geográfica, a região de Ilha das Fontes destacou-se como local de estudo.

O trabalho de campo ocorreu entre os meses de janeiro de 2011 a janeiro de 2012, com variações no período de estadia na comunidade pesqueira, entre 1 a 6 dias. As visitas ocorriam em dias programados pela primeira autora em comum acordo com as informantes identificadas, observando o calendário lunar, o horário de chegada e possíveis alterações marítimas (maré tardeira ou cedeira).

A escolha dos interlocutores ocorreu por indicação da própria comunidade, em conjunto com a observação da primeira autora da pesquisa, sendo escolhidas as que realmente poderiam contribuir para ajudar a responder à questão de pesquisa. Preserva-se a identidade dos entrevistados não revelando seus nomes verdadeiros.

Esse projeto de pesquisa obteve aprovação pelo Comitê de Ética em Pesquisa da Maternidade Climério de Oliveira. Nesse sentido, os aspectos éticos foram contemplados em conformidade com a Resolução

5 Terceiro município brasileiro com maior PIB per capita. Sua população estimada pelo IBGE em 2009 era de 31.699 habitantes. 
CNS 196/96, para pesquisa em seres humanos. Foram promovidas reuniões e apresentação/discussão do projeto com os representantes dos pescadores do município de São Francisco do Conde.

\section{Resultados e discussão}

Famosa pelas inúmeras fontes espalhadas por toda a sua extensão daí o seu nome -, a Ilha das Fontes fica a cerca de $5 \mathrm{~km}$ de São Francisco do Conde. É considerada a melhor água das redondezas, e suas fontes são tidas como as maiores. A Ilha abriga, ainda, as ruínas de um antigo engenho com um legado histórico-cultural amplo. Essa particularidade torna-se representativa quando, nas estatísticas, 95\% da população de São Francisco é negra. É importante salientar que as comunidades pesqueiras da Baía de Todos os Santos são localidades antigas da nação brasileira e se constituem em áreas povoadas por remanescentes de Quilombos desde o século XVI. Nesse sentido é uma região importante pela herança cultural no Brasil; locais onde geralmente persistem sistemas produtivos tradicionais como a produção do pescado.

Conhecer as complexas variações do tempo e suas relações com a movimentação das marés é de fundamental importância em uma comunidade pesqueira. Lua e sol se posicionam de forma variada e cíclica em relação à Terra e determinam a dinâmica das marés, rios e canais litorâneos. Nas fases da Lua nova e cheia, o fenômeno resultante da atração gravitacional exercida pela Lua sobre a Terra, e em menor escala, do Sol sobre a Terra, proporciona uma maior variação das marés, conhecidas como "maré-grande". Contrariamente, nas "marés-mortas", durante os quartos crescentes e minguantes, a atração gravitacional é menor e resultam em marés de fraca elevação.

A divisão territorial na Ilha é feita pelos próprios moradores, a "parte da frente" relativamente descrita anteriormente, a "parte alta", a "ponta" e a "costa". Verifica-se uma infraestrutura habitacional bastante deficitária, com existência de casas de lona, taipa e alvenaria. A infraestrutura social é bastante precária, não existe tratamento de esgotos. Há aproximadamente três anos uma parte da comunidade teve acesso à água encanada. Já o candeeiro deixou de ser utilizado na comunidade há sete anos. 
Na comunidade de Ilha das Fontes não existe assistência médica permanente, a visita médica é realizada uma vez na semana. A demanda relatada por dois funcionários do Programa de Saúde da Família (PSF), enfermeiro e agente comunitária de saúde, segue as proposta das políticas de intervenção básica como programa de hipertensão arterial, diabetes e pré-natal. Com pouco relato de idas ao posto em decorrência de dor ou acidente proveniente do trabalho.

A principal fonte de renda dos moradores é a pesca artesanal (mariscagem, principalmente para as mulheres), observa-se, no entanto, alguns moradores vinculados à prefeitura e com benefícios sociais como: Programa de Assistência Social (PAS) e Bolsa Família. A existência do PAS é uma particularidade do município de São Francisco do Conde.

A imersão no universo pesqueiro da Ilha das Fontes permitiu o tecer histórico de tradição inerente ao ofício de mariscagem, seguindo a compreensão desse espaço feminino e inclusivo, com presença de crianças, idosos e excepcionais; o tecer do aprendizado na maré e a liberdade no território das águas. Apresentam-se as sete etapas do trabalho da mariscagem da ostra: "a preparação para o trabalho", "a ida à maré", "a coleta", "o retorno da maré", "o cozimento do marisco", "a cata do marisco" e "a venda". Nessa longa jornada de trabalho desvendam-se estratégias, mitos, interpretações do corpo, identidade e pertencimento. Assim como surgem relatos de dor, adoecimento e acidentes na maré.

\section{A tradição em ser/tornar-se marisqueira}

O caráter tradicional da pesca é inerente ao ato de pescar, "algo é entregue" de geração a geração para reproduzir-se ao longo do tempo. Não podemos perder de vista que a linguagem é a expressão da experiência vivida e é um dos elementos da realidade. (RICOEUR, 1978) Imbricados nessa lógica transcendental, a vida é relembrada em sua história passada para construção e reconstrução da vida presente. Ao problematizar as noções de tradição e herança cultural busca-se um diálogo com as evidências e com as narrativas orais dos sujeitos. (HALL, 2006) Através da história pregressa de ancestrais pescadores, vivenciam-se situações de extrema dificuldade e adaptações que garantiram a permanência do trabalho nos dias atuais. 
Antes mesmo de nascer, ainda na barriga da mãe o processo de aprendizagem é iniciado e possibilitado por essa construção do simbolismo familiar. (MAUSS, 2003) "Mamãe mariscava, papai vivia na maré". (VERA, 60 ANOS, novembro de 2011) O nascer e crescer na maré é o que permite a prática e o desenvolvimento de habilidades no ofício de mariscagem: a confecção dos instrumentos que maneja com perícia, saber a melhor localização da mariscagem, o tipo de maré, o treino do olhar na identificação do marisco.

A reprodução social da família de pescadores em Ilha das Fontes é intencionalmente estruturada a partir da transmissão dos saberes e elementos socioculturais. (BOURDIEU, 1989) É na infância que esse aprendizado se materializa, sendo circunscrita entre a casa, a rua, a maré e a escola. Nessa fase de reconhecimento do ambiente marítimo, que tradicionalmente são definidos os papéis ocupados pelo homem e pela mulher na comunidade pesqueira. (DIEGUES, 1983) Essa distinção entre os saberes femininos e masculinos ocorre conforme o espaço de construção de identidade e construção social deste mesmo espaço. (BECK, 1989) Na comunidade de Ilha das Fontes são as mulheres que exercem a atividade de mariscagem. Por não possuírem embarcação transitam nas proximidades da costa, seja no mangue ou na "coroa", onde extraem, com auxílio de facas, o "sarnambi" (Phacoides pectinatus), "sururu" (Mytella guyanensis), "tarioba" (Macoma constricta, "chumbinho" (Anomalocardia brasiliana) e "ostra" (Crassostrea rhizophorae).

Esse corpo de saberes orienta o comportamento das marisqueiras, as estratégias de trabalho e também é essencial para prever situações de perigo e dificuldade. Nesse sentido, o conhecimento tradicional ajuda as marisqueiras na construção de seus próprios mapas mentais que as orientam onde e como mariscar, no entrar e sair do mangue. "Dentro do mangue logo minha mãe olhou pro sol e disse - olha Tatiana se a gente vê o sol na nossa direção é o lugar da saída". (TATIANA, 27 ANOS, outubro de 2011)

A percepção visual, para identificação do marisco, ou espacial, para localizar-se no mangue através da analise da posição do sol, se relacionam e se constroem no aprendizado prático, o sentir, o estar ali, o viver o cotidiano da mariscagem interagindo com o ambiente. A percepção constitui-se na interpretação do mundo pelo indivíduo a partir do que 
se vê, sente, cheira, escuta, enfim, apreende com os sentidos. É na existência, o "está ali", que não escapa do passar dos dias, que se cria, se imagina, se sente, se entende a vida, a vida na maré.

Sobre tal fato, Diegues (1983), ao caracterizar o pescador artesanal, diz que o ponto definidor deste não se resume ao ato de viver da pescaria, mas dominar plenamente, os meios de produção da pesca. O que possibilita a mariscagem é a autonomia de trabalho, pois o saber-fazer compreende o controle dos processos de confecção e conserto dos instrumentos, e conhecimento da mariscagem, que permitem gerar esse sentimento de ser liberto, por apresentar a qualidade de certa "independência" no que concerne ao "mundo externo" à pesca. "A melhor coisa é trabalhar com as coisas que é seu, trabalhar com as coisas dos outros é ruim, é muita humilhação". (JACQUELINE, 34 ANOS, outubro de 2011)

O principal aspecto positivo é o fato de trabalharem para si mesmas, além de não terem horário fixo. Neste sentido, identificam a liberdade como uma das características da atividade de mariscagem. Essas relações emergem em um contexto de liberdade, compreendida como o poder fundamental que se tem de ser o sujeito de todas as experiências, não se distingue de sua inserção no mundo. (MERLEAU-PONTY, 1999)

A liberdade do trabalho na maré não é determinada exteriormente, imposta por gerências, mas interiormente, de natureza subjetiva, determinada pelas condições sociais de sobrevivência. Dessa forma, quando há falta de alimento para a família ou dinheiro para gastos relativos à sobrevivência, tais necessidades econômicas impõem os ritmos de trabalho e vida nas comunidades pesqueiras.

Ao se projetar para o futuro pode-se inferir que a transmissão dos saberes específicos sobre a pesca artesanal/mariscagem poderá perderse ou ser ignorada entre as novas gerações. Observa-se que, os mais jovens são atraídos pelas possíveis ofertas de emprego no setor de serviços, na expectativa de uma melhor qualidade de vida e trabalho.

Em meio a essa circunstância observa-se outra relacionada ao pertencimento à comunidade pesqueira. (HALL, 2006) Mesmo que os mais jovens partam em busca de novas perspectivas de trabalho, as relações com o mar permanecem constituindo a base da sustentabilidade nos momentos de retorno à comunidade em decorrência do desemprego. A sobrevivência da pesca artesanal/mariscagem parece apontar para 
uma resistência enquanto o "fazer", enquanto "forma de trabalho", que envolve a história familiar, cultural, geográfica de aprendizado e, sobretudo, a garantia de quando tudo lhe faltar, o mar estará sempre a servi-lhe os recursos da sobrevivência.

Uma vez que os moradores de alguma forma são relacionados uns aos outros pelo parentesco, a reciprocidade entendida aqui como a experiência da retribuição e necessidade de cooperação, configura-se como um elemento estrutural e estruturante para a constituição da rede de sociabilidade, e por conseguinte da sobrevivência do povoado. (LÉVI-STRAUSS, 1982; SCHUTZ, 1979)

\section{O trabalho no mangue: a coleta da "ostra"}

Através das narrativas das marisqueiras e das "lentes"6, que buscam conhecer, vivenciar, compreender e interpretar o fenômeno, com o suporte da análise ergonômica, observa-se que o trabalho da marisqueira de Ilha das Fontes contempla em geral sete etapas. Um dia o trabalho pode iniciar-se às 7 horas da manhã e findar-se 12 horas depois, noutro a saída é feita com o dia ainda escuro só retornando ao fim da tarde. (GUERIN et al., 2001)

Tanto as saídas como os retornos dependem da maré, a descobrir e encobrir a fonte de sobrevivência dessa gente que dela vive. Em meio a essa jornada de trabalho permeiam outras, pois a elas cabem o cuidar dos filhos e companheiros, os afazeres domésticos e o preparo da alimentação.

As interações entre o ciclo do dia, o ciclo da maré e o ciclo produtivo com a casa, a natureza e o cotidiano, reflete a existência de relações sobrepostas entre o trabalho na maré e a vida de uma marisqueira. Representam a teia de relações, muitas vezes, implícitas, inerentes ao mundo da pesca artesanal, mais especificamente, na atividade de mariscagem.

A compreensão das etapas que constituem o trabalho na maré, neste caso o marisco "ostra", é apreendida no lócus da atividade, na

6 Lentes de quem acredita existirem inúmeras formas de ver e interpretar o que é visto, considerando-se que valores e comportamentos formadores de diferentes identidades permeiam essas formas diversas de olhar o outro e de, a posteriori, como refletindo a imagem de um espelho, tecer novo olhar sobre si mesmo (GERBER, R. M. Temporalidade pesqueira e espaços feminino e masculino em Ganchos. In: RIAL C; GODIO, M. (Org.) Pesca e turismo: etnografias da globalização no litoral do Atlântico Sul, Florianópolis: NUPPE/CFH/UFSC, 2006. p.113-128). 
interpretação das narrativas e na experimentação do corpo em atividade através da experiência na Ilha das Fontes.

\section{As Etapas do trabalho}

$1^{a}$ Etapa: a preparação para o trabalho - o que vestir, o que levar, o que comer?

O corpo frágil construído socioculturalmente para a mulher perde significado nas comunidades pesqueiras. Corpos que ganham forma e força não pela construção metódica e racionalizada por meio de exercícios programados, alimentação balanceada, ingestão de substâncias sintéticas ou cirurgias, mas pelo trabalho manual/braçal realizado na maré. Esse corpo forte no trabalho é comparado, por elas, ao corpo do homem, capaz de realizar "atividades de homem".

Vestem-se para o trabalho utilizando os recursos que lhes são disponíveis para amenizar os riscos a que são expostos. Definem o abastecimento nem sempre o necessário para a manutenção da longa jornada na maré/mangue, mas o possível economicamente ao dia de trabalho. Em dez minutos estão prontas para iniciar a jornada. Também confecciona e improvisa os instrumentos de trabalho da mariscagem, uma faca ou facão para retirada da "ostra" e um balde para o transporte, como é observado na Figura 2. Nessa relação de "pertencimento" transparece a expressão de independência e autonomia do trabalhador da maré/mariscagem. (HALL, 2006) 
Figura 2 - Instrumentos de trabalho

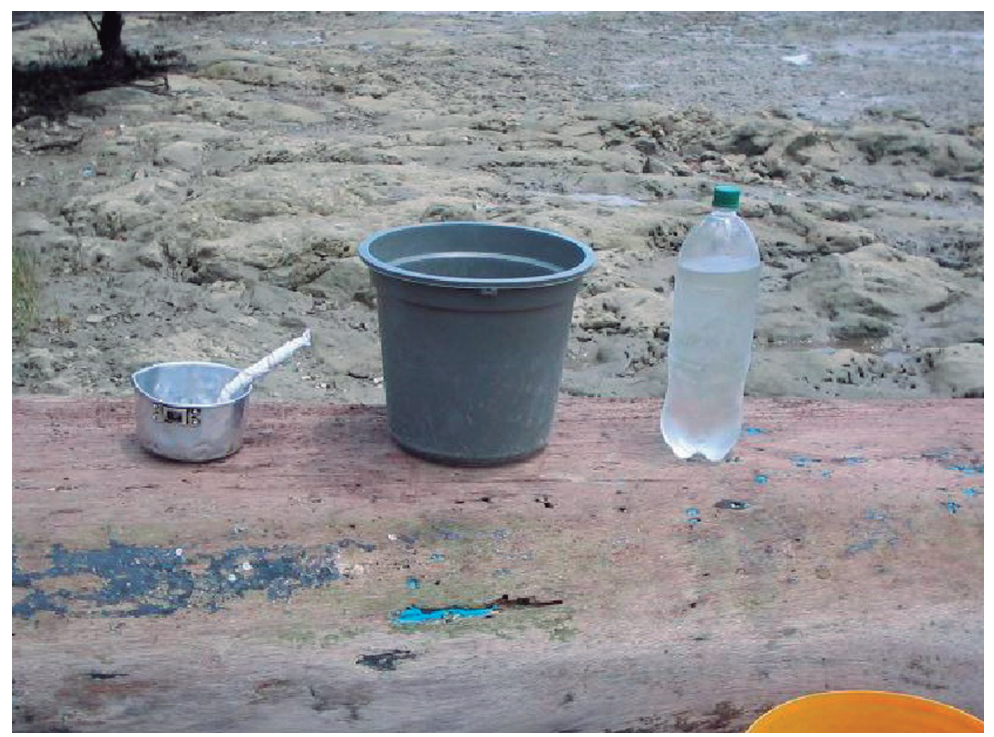

Fonte: Fotos da pesquisa (GOMES, 2011)

\section{$2^{a}$ Etapa: ida à maré/mangue}

Na Ilha das Fontes, diferente do que ocorre em outras regiões pesqueiras, o trajeto ao mangue tem duração de vinte minutos, facilitado pela proximidade das casas às áreas de extração da ostra. Porém, não a isenta do olhar atento aos perigos do trajeto. A depender do local de coleta e do tipo de marisco coletado encontram-se novas dificuldades, necessitando de preparo para enfrentá-las. As vestimentas, os esforços, a habilidade do corpo ao transitar em regiões de mangue são diferenciadas. Nesse ambiente, a possibilidade de afundamento é grande, para isso estratégias de como caminhar de forma ágil e firme são passadas para evitar acidentes. O calçado preso ao pé é necessário para evitar cortes, assim como calça e camisa comprida para proteger do sol e de mosquitos.

No entanto, o uso de óleo diesel ${ }^{7}$ na pele é frequente para inibir a picada dos mosquitos. Na maré grande há mais mosquitos, o que difi-

7 Segundo dados do National Institute for Occupational Safety and Health (NIOSH, 1988), a exposição ao óleo diesel pode provocar câncer. 
culta o trabalho. Segundo Guérin e colaboradores ${ }^{8}$ (2005), o contexto geográfico influencia as condições de deslocamento ao local de trabalho e, portanto, as interações entre sua atividade de trabalho.

\section{$3^{a}$ Etapa: coleta da "ostra"}

A imagem vista nos manguezais configura-se como um mosaico de corpos, ora com a coluna fletida, apoiando-se em uma das pernas, ora agachadas e sentadas sobre os calcanhares "cócoras". No momento da coleta, o tronco é inclinado "envergado" para frente, apoiando-se com um braço sobre uma das pernas o que lhe permite um leve descanso. $\mathrm{O}$ outro fica livre para segurar o instrumento que dá continuidade a sua mão. Essa inclinação perdura por horas, cotidianamente, entre as raízes de manguezais, de tal forma que com elas se assemelham (Figura 3). Muitas vezes, para possibilitar a extração de mais "ostras", a marisqueira aguardava sentada nas galhas do manguezal o segundo ciclo da maré para continuar a coleta. Observam-se rápidos e precisos movimentos com as mãos.

O ambiente de mangue ainda exige outras posturas, pois muitas vezes a lama encobre as pernas, chegando à região da cintura. Exige equilíbrio e agilidade para não cair ou atolar. "Uma vez atolada, só com a ajuda de alguém para nos tirar do buraco que nosso corpo desenhou na lama". (DIÁRIO DE CAMPO, set./2011). O risco de afogamento na lama revela os perigos do mangue e a preferência pelo trabalho na costa "coroa".

O tempo tomado pelo trabalho é quase absoluto, cinco a seis horas. Dispensava-se qualquer treinamento extra. A marisqueira aprende silenciosamente os gestos, a utilização de forças, as estratégias de trabalho, o melhor local para retirada do marisco/ostra. Aprende a lidar com os ciclos do seu corpo (menstruação, gravidez, amamentação) e o trabalho na maré. Surgem mitos impressos no corpo da mulher, o útero que interioriza a lama do mangue como me explica Tatiana (27 ANOS, out./2011):

[...] no mangue a mulher não pode mariscar porque a mulher tem útero, e para mariscar no mangue é mais arriscado que o homem, minha mãe contava de uma moça que morreu e no exame transvaginal o médico viu o útero dela

8 Guérin e colaboradores (2005) são utilizados como referências na análise ergonômica do trabalho para auxiliar na compreensão e interpretação do trabalho na maré. 
cheio de lama de mangue, ela mariscava abaixada, o vapor do salitre às vezes caía no buraco, a lama introduzia e entrava, passava às vezes com lama na cintura, ela terminou se prejudicando.

Uma característica da prática médica é não se basear em um conhecimento propriamente dito quando se trata de explicações das classes populares. (BOLTANSKI, 2004) A comunicação médico/paciente esbarra nas barreiras linguísticas e analogias feitas para facilitar a compreensão, porém as explicações são geralmente vagas e o confundimento propicia os mitos.

Por ser um trabalho realizado em ambiente aberto, as marisqueiras estão sujeitas às mudanças de temperatura. A umidade, as temperaturas instáveis, a maresia, deveria haver ali uma aprendizagem, uma educação, sobretudo uma autoeducação dos sentidos, para suportar as dificuldades do ofício. (ZOLA,1979) Autoaprendizagem para sobreviver. E assim como os mineradores de Émile Zola, o corpo da marisqueira com o tempo também parece gastar menos energia, internaliza os códigos da economia de força sem nenhuma explicação científica, mas tão somente essa enorme capacidade que tem o ser humano de adaptarse para não morrer, antes de buscar as formas de transformar, para daí viver. (ZOLA, 1979)

Figura 3 - Coleta 'coluna fletida'

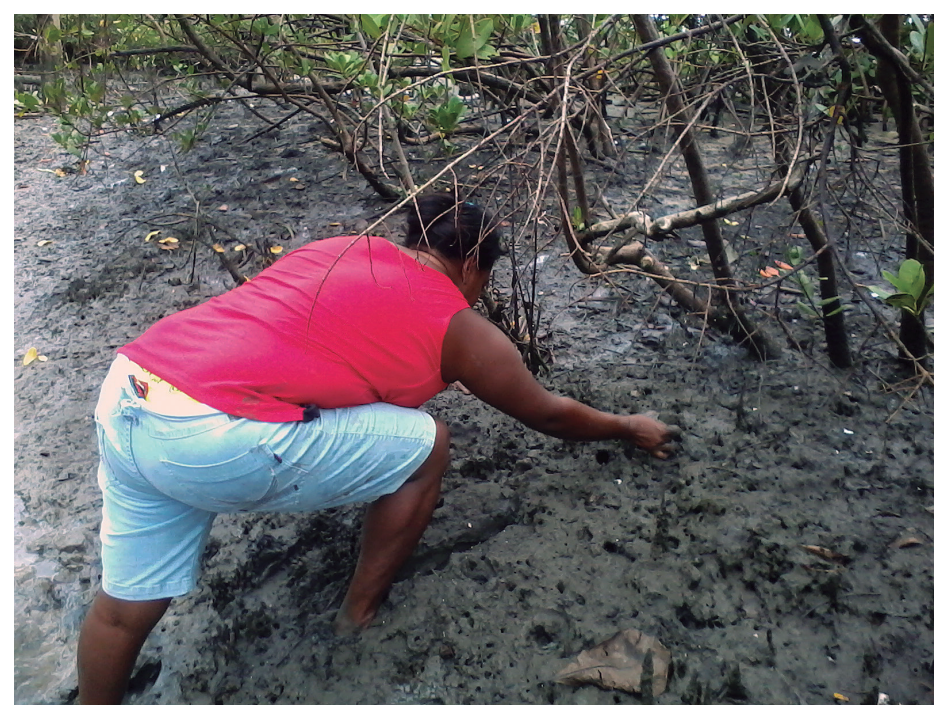

Fonte: Fotos da pesquisa (GOMES, 2011) 


\section{$4^{a}$ Etapa: retorno da maré}

O mesmo trajeto de ida é percorrido, porém com o sobrepeso da "ostra" que pode variar entre 20 ou 40 quilos, a depender da maré/ mangue, realizado em aproximadamente trinta minutos. No retorno do mangue a marisqueira se percebe e é percebida pelos que lá não estavam como suja. Há uma rejeição, um conflito com isso, que não está na dimensão corporal. Há um conflito na própria identidade de marisqueira, que se faz não apenas pelas habilidades que adquiriu na maré, mas porque ela é aquela que vai ao mangue e que fica "suja, com mau cheiro" e vira mangue também, essa relação segundo o Centro de estudos e pesquisas Josué de Castro (2001) qualifica-se como verdadeira simbiose.

Os odores da vida cotidiana representam a intimidade mais secreta do indivíduo: fragrâncias do corpo, das roupas, das casas, dos ambientes. Para percebê-los é necessário, o efeito, o contraste, a indiferença. (LE BRETON, 2011) Aliás, é através do odor que imediatamente se recorre quando se trata de difamar ou discriminar o outro.

O discurso social estigmatiza antes os odores como "maus" e associa a feminilidade à presença de cheiros doces, diferente do cheiro do corpo que trabalha no mangue. O odor corporal exalado pelo corpo constitui a "assinatura de sua presença no mundo". (LE BRETON, 2011, p.180) Dessa forma Vera nos explica esse pertencimento ao mangue é próprio do ofício da mariscagem. "Não é todo mundo que vem aqui não, para ser marisqueira tem que mariscar, entrar no mangue, se atolar - [risos]. (DIÁRIO DE CAMPO, 2011)

\section{$5^{a}$ Etapa: o cozimento da "ostra"}

Arruma-se a ostra em uma panela para fervê-la no fogo à lenha (Figura 4). Lenha que é extraída previamente nos arredores da Ilha. Corta-se a lenha ou fazem uso de galhas que já encontram ao chão. A fumaça invade os poucos cômodos existentes. Uma fumaça que invade não só a casa, mas o corpo, após a inalação a tosse não demora a aparecer. Com toda aquela fumaça os olhos ardem, o nariz irrita, mas com o passar do tempo o corpo parece se acostumar. O momento do cozimento e da cata sobrepõe-se no ir e vir de cozer a "ostra", inalar fumaça, carregar panela e despejar na bacia perdura, até que a última "ostra" seja cozida. 
Figura 4 - Cozimento do marisco

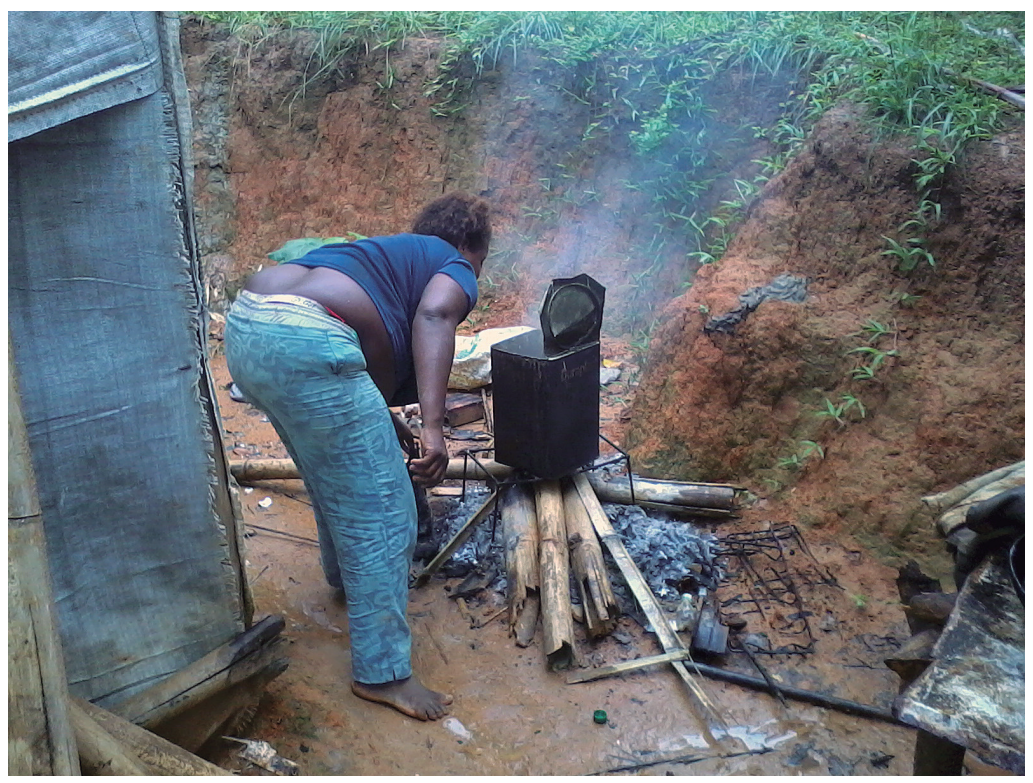

Fonte: Fotos da pesquisa (GOMES, 2011)

\section{$6^{a}$ Etapa: a cata do marisco}

"Ela cata sentada ao chão, onde também estão os mariscos depositados em pequenas vasilhas, além de animais (gatos ou cachorros) a transitar". (DIARIO DE CAMPO, Out./2011)

Rodeada pelas ostras (Figura 5), a vida parece não ser guiada por nenhuma lógica de tempo. O trabalho termina quando a última ostra é aberta, muitas vezes após seis horas de cata. Todos os processos da ostra pareciam ser mais difíceis, sua coleta, seu transporte, seu cozimento e sua cata. O conhecimento prático observado na execução do ofício de marisqueira é um dos domínios das técnicas corporais. Segundo Le Breton (2007), esse conhecimento é resultado da competência profissional sedimentada em um conjunto de gestos de base, assim como um grande número de movimentos coordenados nos quais o homem cristaliza, com o passar dos anos, sua experiência secular. "Trata-se de modalidades de ação de sequencias de gestos, de sincronias musculares que se sucedem na busca de uma finalidade precisa". (LE BRETON, 2007, p. 39) Segundo Merleau- Ponty (1999, p. 198) “a aquisição do 
hábito é sim a apreensão de uma significação, mas é a apreensão motora de uma significação motora".

É no momento da cata que o corpo encontra no ambiente doméstico, não só a catar, mas intercalar com o cuidar dos filhos que já retornaram da escola, o cuidar da comida e dos afazeres da casa. Apesar do esforço repetitivo inerente à etapa, este é o momento mais agradável.

Figura 5 - Cata do marisco

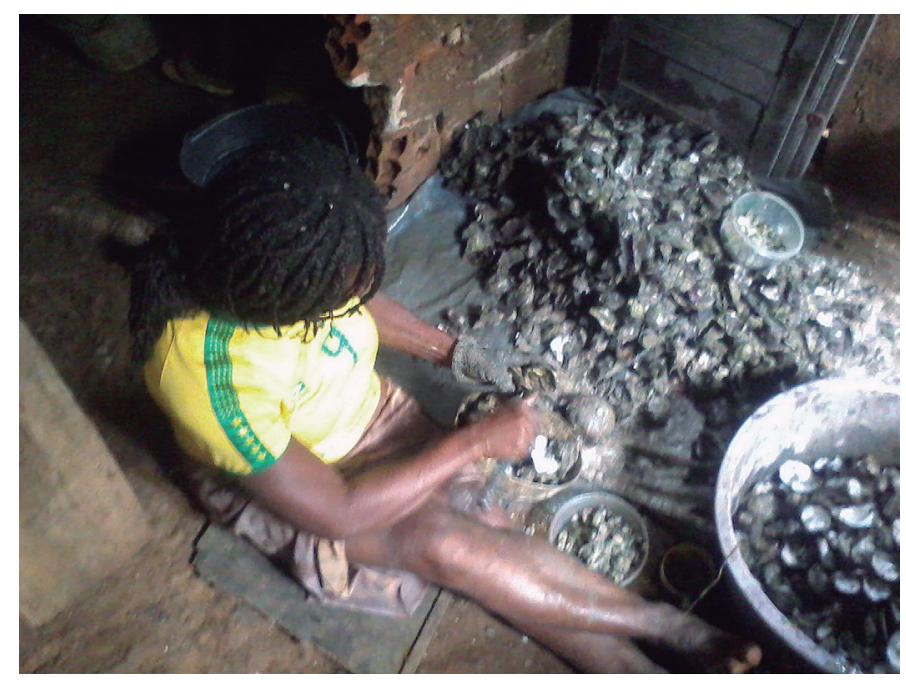

Fonte: Fotos da pesquisa (GOMES, 2011)

\section{$7^{a}$ Etapa: a venda}

Nesse cotidiano de trabalho a semana passa, para aos sábados ocorrer o deslocamento para Candeias, local onde acontece a venda dos mariscos. Lá, também são realizadas as feiras da semana, com o próprio dinheiro adquirido com a venda. Vende-se um alimento para comprar outros alimentos.

O corpo cansado da jornada de trabalho semanal não pode deixar de atravessar a Ilha em direção a Candeias, lá a feira é movimentada e passam até cinco horas a vender seus mariscos. Em barracas eles se misturam às verduras, às frutas, ervas medicinais e tantos outros pequenos produtos para consumo. A venda também acontece na própria Ilha. 
No entanto, há de se ressaltar que para as marisqueiras, não há férias, descanso semanal e feriados remunerados. A decisão do não trabalho implica na perda da produção correspondente. Um dia que não seja dispensado ao trabalho, muitas vezes, representa ter que desinteirar o quilo já armazenado.

Esse trabalho expresso nas adversidades do campo, realizado sobre condições extremas de esforço e jornada de trabalho exaustiva; sujeito a intempéries e acidentes na maré/mangue é percebido com dores e odores. Ao tempo vivencia a vulnerabilidade social em que se inserem as comunidades pesqueiras, mantêm-se na sua tradição oral, perpassando gerações e possibilitando a sobrevivência da população que dela vive.

\section{Dor: um modo-de-ser-no-mundo}

O trabalho e a força física utilizada na execução da atividade determinam, em certo ponto, a compreensão e a experiência das enfermidades. Para construir uma explicação mínima para o fenômeno da doença, os indivíduos não necessitam do conhecimento biomédico. Ao contrário, as imagens fornecidas pela sua cultura compõem a rede de significados que lhe permite entender os diferentes eventos, como por exemplo, a doença. (GEERTZ, 1989) Assim, não lhes basta somente conhecer os agentes causadores, através de técnicas de diagnóstico. A experiência da doença não se resume ao sucesso ou insucesso desta ou daquela forma de diagnosticá-la e tratá-la, mas, sobretudo retrata uma visão e posição no mundo daqueles que a vivenciam. (ALVES; SOUZA, 1999)

Cada atividade laboral impõe diferentes demandas ao corpo do trabalhador, com diferentes respostas desde o cansaço (fadiga) à dor muscular aguda ou crônica. No estudo apresentado, a percepção da doença é possibilitada por sinais e sensações corporais como cansaço e fraque$\mathrm{za}$, indicando que algo impede o funcionamento "normal" do corpo. No ofício de mariscagem, a fadiga corporal geral (disease) entendida pelo modelo biomédico, é diagnosticada através de presença de movimentos repetitivos, posturas adotadas no trabalho no mangue. (PENA; FREITAS; CADIJM, 2011) Pretende-se neste estudo ampliar signos e significados expressos nesse cansaço.

O trabalho impõe ao corpo uma continuidade de etapas, longa jornada, carregamento de peso, posturas, gestos, movimentos repetitivos. Ao narrarem o "cansaço da maré", elas revelam seu aparecimento prin- 
cipalmente após as etapas desenvolvidas fora do ambiente doméstico. Esse cansaço cessa quando é possível um repouso, no entanto, mesmo à noite, enquanto "[...] os demais operários cansados do labor diurno metem-se na cama para passarem comodamente à noite, num sono reparador, as noites dos pescadores estão cheias de trabalho e insônias". (RAMAZZINI, 1985)

Esse perceber da doença expressa à importância social do corpo como meio de existência para aqueles que dele dependem para sobreviver. Não somente uma parte do corpo dói, este corpo dói por inteiro, é o "cansaço da maré", percebido como físico, mas também mental. Nesse contexto, o trabalho acontece, o cansaço desaparece para novamente reaparecer após um novo dia de trabalho. Com o passar dos anos de trabalho, essa fadiga torna-se sinal de fraqueza impedindo a continuidade do trabalho como relata Tatiana (27 ANOS, out./2011): "Eu estava fraca, chegava em casa tinha vez que eu nem catava no mesmo dia, não aguentava mais”. E assim, Vera questiona-se sobre a necessidade de parar, pois o corpo já não mais consegue dar conta de tantas fadigas acumuladas no trabalho. "A maré cansa a pessoa, tendo a idade assim é mais para continuar na maré?”. (VERA, 60 ANOS, nov./2011)

A sobrecarga de trabalho, associada às mínimas condições materiais, limita a vida dessas trabalhadoras das águas a movimentos de revolta às situações insuportáveis dentro das fronteiras que aprenderam a tolerar, onde a violência que os atinge é sutil, é escamoteada na hipersolicitação do corpo, no cansaço, na dor e nos acidentes que os atinge.

\section{Considerações finais}

Diante de uma atividade de caráter artesanal, sem as gerências próprias do contexto industrial, onde a tarefa é prescrita pela tradição cultural, o mergulho nas histórias e narrativas dos saberes tradicionais e a observação do trabalho na maré foram necessários mediante as abordagens etnográfica e ergonômica. As atividades na terra são exercidas por mulheres, além de possibilitar a inclusão do trabalho de crianças, idosos e pessoas com necessidades especiais. São reconhecidas como marisqueiras e exercem uma atividade que envolve tradições tecidas geração após geração, desvendando os caminhos da arte de ser marisqueira. Detentoras de um vasto arsenal de saberes marítimos, elas criam e 
recriam um modo de ser no mundo, através do habitus de vida singular. (BOURDIEU, 1989)

O mangue, local de riquezas, mitos, ritos e perigos, é sinalizado como o ambiente mais difícil à realização do ofício de marisqueira. A caracterização da tarefa nesse contexto permitiu identificar as variabilidades do trabalho no mangue, com presença de movimentos repetitivos; posturas adotadas como flexão de coluna por tempo prolongado; evidenciando como são geradas as demandas extras e como as exigências cognitivas e físicas podem ser exacerbadas pela demanda temporal da maré. As precárias condições de trabalho, com uso mínimo de equipamentos de proteção individual expõem essas trabalhadoras a riscos de acidentes e adoecimento no trabalho.

Porém, é possível afirmar que a mariscagem extrapola e recria os significados do trabalho, que vai além da necessidade de sobrevivência, possibilitando liberdade e prazer para as mulheres que dela vivem. As reflexões contidas nesse estudo permeiam horizontes extremos de mesmo cenário. De um lado o desamparo social que impõe às marisqueiras um estado constante de vulnerabilidades. Do outro, o amparo circunscrito na riqueza das tradições orais, na liberdade do ofício, no domínio dos meios de produção, em programas assistenciais como o PAS e a bolsa família, o que lhes permitem sair da linha tênue da extrema miséria às condições mínimas de sobrevivência.

As implicações desse estudo ao trabalho na maré ratificam a necessidade da compreensão sociocultural e valorização da tradição e do prazer na arte de mariscagem para proposição de medidas preventivas ao trabalho. Compreender o trabalho para transformá-lo faz-se necessário à medida que as intervenções de caráter preventivo na comunidade sejam condizentes com o habitus de vida e trabalho. (GUERIN et al., 2005) A imposição de práticas como pausas, alongamentos, exercícios não garantem a adoção destas pela comunidade, pois a maré não segue a lógica da ginástica laboral em uma empresa. As negociações de ações preventivas são articuladas em campo, em conjunto com elas, estabelecendo limites e possibilidades à sua realização.

Não buscamos discussões especulativas com relação ao fim da atividade pesqueira artesanal, pois inúmeras seriam as repercussões não apenas nas comunidades que dela vivem, mas também para as regiões que consomem o produto final de seu trabalho, o marisco. Assumir a 
discussão da pesca artesanal, em especial do trabalho exercido pelas mulheres na mariscagem, permitiu uma aproximação do trabalho na maré, não apenas com o olhar da avaliação biomecânica realizada pela Fisioterapia, mas extrapolando esse olhar sistemático para compreendê-lo em sua dimensão subjetiva e cultural. Um corpo forte, moldado pelo trabalho braçal, impregnado de lama do mangue, e por isso sujo e com odores, mas que tolera a dor no trabalho para continuar sobrevivendo dele.

As devolutivas do estudo seguem como prioridades na continuidade dos estudos desenvolvidos em comunidades pesqueiras, visando melhorias nas condições de vida e trabalho. Um importante passo foi dado no que concerne à compreensão do cenário da mariscagem na Ilha das Fontes. As proposições aqui levantadas emergiram nesse contexto e dessa forma, possibilitarão a ampliação de novos debates.

\section{Referências}

ALVES, P. C; SOUZA, I. M. Escolha e avaliação de tratamento para problemas de saúde: considerações sobre itinerários terapêuticos. In: RABELO, M. C; ALVES, P. C.; SOUZA, I. M. Experiência de doença e narrativa. Rio de Janeiro: Editora Fiocruz, 1999. p. 125-38.

ARNASON, R. General Profile. In: ILO - International Labors Organization. Encyclopedia of Occupational Health and Safety, 1998. Disponível em: <http://www.ilo.org/safework_bookshelf> Acesso em: 18 jan 2011

BAHIA Pesca. Boletim estatístico da pesca marítima e estuarina. Bahia: [s. n. ], 2005.

BECK, A. Pertence à mulher: mulher e trabalho em comunidades pesqueiras do litoral de Santa Catarina. Rio Grande do Norte, Natal: 1989. (Programa de pesquisa e conservação de áreas úmidas do Brasil, IOUSP - F. Ford - IUCN) Fórum de discussão sobre o universo social da mulher, a pesca e sua relação com a ecologia. [s. n].

BOLTANSKI, L. As classes sociais e o corpo. São Paulo: Paz e Terra, 2004. BOURDIEU, P. O poder simbólico. Lisboa: Difel, 1989.

BRASIL. Ministério da Pesca e Aquicultura Boletim Estatístico da Pesca e Aquicultura - Brasil 2008 - 2009, Brasília, 2011. 100 p.

CASTRO, J. de. Homens e caranguejos. Rio de Janeiro: Civilização Brasileira, 2001. 
CENTRO de Estudos e Pesquisas Josué de Castro. Trabalho da mulher pescadora em comunidades pesqueiras do litoral de Pernambuco: sistematização preliminar para correções/reformulações. In:

TALLER latino-americano sobre gênero e o trabalho da mulher em comunidades pesqueiras costeiras. Recife, maio 2000.

DIEGUES, A. C. S. Pescadores, Camponeses e Trabalhadores do Mar. São Paulo: Ática, 1983.

DIEGUES, A. C. S. A pesca construindo sociedades: leituras em antropologia marítima e pesqueira. São Paulo: Núcleo de Apoio à Pesquisa sobre Populações Humanas e Áreas Úmidas Brasileiras/USP, 2004.

FAO, Food and Agriculture Organization of the United Nations. The State of World Fisheries and Aquaculture. 2006.

GEERTZ, Clifford. A Interpretação das Culturas.

Rio de Janeiro: Guanabara Koogan, 1989.

GERBER, R. M. Temporalidade pesqueira e espaços feminino e masculino em Ganchos. In: RIAL C; GODIO, M. (Org. ) Pesca e turismo: etnografias da globalização no litoral do Atlântico Sul, Florianópolis: NUPPE/CFH/UFSC, 2006.

GUÉRIN, F. et al. Compreender o trabalho para transformá-lo: a prática da ergonomia. São Paulo: Edgard Blucher, 2001.

HALL, S. Notas sobre a desconstrução do popular. In: HALL, S. Da diáspora: identidades e mediações culturais. Belo Horizonte: Ed. UFMG, 2006.

IBAMA. Monitoramento da atividade pesqueira no litoral do Brasil - Projeto ESTATPESCA: relatório final. Convênio SEAP/IBAMA/ FROZZE nº109/2004, Brasília, 2006.

IUCN. Global Status of Mangrove Ecosystems. Commission on Ecology Papers. International Union for Conservation of Nature and Natural Resources, Gland, Switzerland. n. 3, 1983.

LAPLANTINE, F. Aprender Antropologia. São Paulo, Editora Brasiliense, 2003.

LE BRETON, D. A Sociologia do corpo. Petrópolis-RJ: Editora Vozes, 2007. Antropologia do corpo e modernidade.

Petrópolis-RJ: Editora Vozes, 2011.

LEITÃO, M. R. A. O Papel da mulher no desenvolvimento local. Recife: Editora FASA, 2009. 
LÉVI-STRAUSS, C. As estruturas elementares do parentesco. Petrópolis-RJ., Vozes: 1982.

MAUSS, M. Sociologia e antropologia. São Paulo: Cosac/Naify, 2003

MERLEAU-PONTY, M. Fenomenologia da percepção.

São Paulo: Martins Fontes, 1999.

OLIVEIRA, R. C. de. O Trabalho do antropólogo. Brasília/

São Paulo: Paralelo Quinze/Editora da Unesp, 1998.

PENA, P. G. L; FREITAS, C.; CADIM, A. Trabalho artesanal, cadências infernais e lesões por esforços repetitivos: estudo de caso em uma comunidade de mariscadeiras na Ilha de Maré, Bahia.

Ciência \& Saúde Coletiva, v. 16, n. 8, 2011, p. 3383-3392.

RAMAZZINI B. As doenças dos trabalhadores. São

Paulo: Fundacentro/Ministério do Trabalho, 1985.

RIAL, C. Revisitando a etnografia Mar-de-dentro: pesca, turismo e a transformação do espaço social. In: RIAL, C; GODIO, M.

(Org. ). Pesca e turismo: etnografias da globalização no litoral do Atlântico Sul. Florianópolis: NUPPE/CFH/UFSC, 2006.

RICOUER, P. O conflito das interpretações: ensaios de hermenêutica. Rio de Janeiro: Imago, 1978.

. Tempo e Narrativa. Campinas: Papirus. 1994.

SCHUTZ, A. O mundo das relações sociais. In: WAGNER, H. R. (Org. ). Fenomenologia e relações sociais: textos escolhidos de Alfred Schutz. Rio de Janeiro: Jorge Zahar, 1979.

VANNUCCI, M. Os manguezais e nós: uma síntese de percepção. São Paulo: Editora da Universidade de São Paulo, 1999.

ZOLA, É. Germinal. São Paulo: Abril Cultural, 1979. 